\title{
A Test of Hansen's Method with Irregular Boundaries
}

by

\author{
Gordon W. Groves ${ }^{1)}$
}

\begin{abstract}
Free, long seiches in a rectangular basin were simulated with Hansen's method applied in two ways: (1) with the basin boundaries coinciding with the grid coordinate axes, and (2) with the basin boundaries inclined 45 degrees to the grid axes. There was good agreement between the two cases, and with the theoretical solutions.
\end{abstract}

\section{Introduction}

In connection with a planned numerical study of wind-driven circulation in the shallow seas of Indonesia, it was thought worthwhile to first make a simple test of the procedure in a geometrically simple basin. The purpose of the test was to gain general familiarity with Hansen's method in order to apply it to the planned circulation study, and particularly to see if representation of all boundaries by meridional and latitudinal segments introduces severe undesirable effects. No new scientific results are presented.

The method used is described by Brettschneider (1987; section 1.3.4), except that here the procedure was further simplified by neglecting bottom friction and the nonlinearity arising from finite surface elevation (in relation to water depth), as well as the stabilizing dissipative terms suggested by Neumann and Richtmyer (1950). The resulting equations then become

$$
\begin{aligned}
& U(t+\Delta t)=U(t-\Delta t)+2 \Delta t \rho V(t-\Delta t)-\frac{g \Delta t}{h}\left(Y_{m+1}-Y_{m-1}\right) \\
& V(t+\Delta t)=V(t-\Delta t)-2 \Delta t f U(t-\Delta t)-\frac{g \Delta t}{h}\left(Y_{n+1}-Y_{n-1}\right) \\
& Y(t+2 \Delta t)=Y(t)-\frac{\Delta t}{h}\left[(H U)_{m+1}-(H U)_{m-1}+{ }_{n+1}^{(H V)}-(H V)_{n-1}\right]
\end{aligned}
$$

1) On sabbatical leave from Department of Oceanography, University of Hawaii, presently attached to Lembaga Penelitian Lau«t to work under SEAMEC Program. 
with the meaning of the symbols as follows:

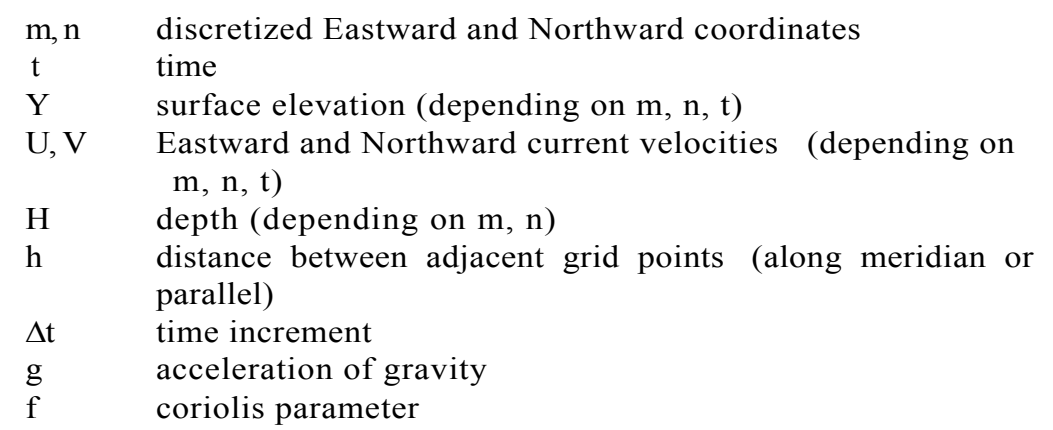

The case where the boundary is inclined 45 degrees to the grid coordinate axes is an extreme case most likely to cause trouble. In this case the grid boundary must be jagged, or serrated, in order to lie as closely as possible to the actual boundary of the basin. Minimum deviation between grid and basin boundaries is achieved by making each 'tooth' of the serrated grid boundary as small as possible, i.e., of length $2 \mathrm{~h}$ on each side (see figure 1). Note that at each corner of the grid boundary (either salient or indentation) nothing is calculated. However at the intermediate points either $\mathrm{U}$ or $\mathrm{V}$ must be maintained equal to zero. Two questions arise: (1) how well does the Hansen grid simulate such an inclined boundary, and (2) how closely would water motion in an actual basin with a serrated boundary correspond to motion in a basin with a straight, inclined boundary? The second question is beyond the scope of the present discussion, but if the answer to it were, "poorly" it would seem unlikely that the answer to the first question would be any better, as presumably a serrated Hansen grid boundary would simulate an actual basin with corresponding serrated boundary reasonably well. Since the results of the present test indicate that a grid with serrated boundary simulates well an actual basin with a straight (inclined) boundary, it must follow that small serrations in the boundary of an actual basin have little effect on the water motion. (This interesting question cannot be pursued further here, but of course one of the effects of actual serrations would be to create turbulence and increase the diffusion of momentum enhancing the boundary friction, an effect which is neglected in the simplified Hansen equations.)

\section{The Rectangular Basins}

Two rectangular basins, $A$ and B, are simulated. Each has a depth of 4 $\mathrm{km}$. A grid mesh length of $100 \mathrm{~km}$ and $\Delta \mathrm{t}$ of $200 \mathrm{sec}$ is used in both cases. (This combination satisfies the convergence and stability criteria.) Basin A is oriented so that its boundaries coincide with meridians and parallels, while basin $\mathrm{B}$ is inclined 45 degrees relative to basin $\mathrm{A}$. The other characteristics of the basins are as follows: 


\begin{tabular}{|c|c|c|}
\hline & Basin A & Basin $\mathbf{B}$ \\
\hline Length & $38 \mathrm{~h}$ & $38.18 \mathrm{~h}$ \\
\hline Width & $24 \mathrm{~h}$ & $24.04 \mathrm{~h}$ \\
\hline 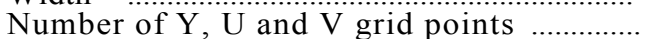 & 715 & 734 \\
\hline $\begin{array}{l}\text { Approximate number of iterations in one peri } \\
\text { of gravest gravity seich mode }\end{array}$ & 192 & 193 \\
\hline
\end{tabular}

\section{The Gravity Wave Test}

The first test was made taking the coriolis parameter $\mathrm{f}$ to be zero. Initial conditions $\mathrm{U}=0, \mathrm{~V}=0$, and $\mathrm{Y}$ representing a plane surface sloping along long axis of rectangle, were taken in each case. (The initial conditions on $U$ and $\mathrm{V}$ were applied actually at a time $\Delta \mathrm{t}$ later than the initial $\mathrm{Y}$ condition, but this discrepancy is minor.) The motion in each basin was iterated for two complete oscillations. The results are shown in figures $2-5$. The period of numerical oscillation was determined by letting the iteration procedure run for just under two periods of time, and then displaying the surface-elevation field after each iteration and selecting that display which appears to represent the maximum point of the oscillation. Thus 194 iterations in basin A, 200 in basin B, was obtained as the approximate time for two complete oscillations. The difference between these values and those indicated in the above table can be ascribed to a failure of the difference equations to model precisely the water motion in the real, continuous case. Similar discrepancies are noted in the final configuration of the. surface elevation, which should have returned to exactly the initial configuration. It is noted that the amplitude in basin A suffers an attenuation of about $6 \%$ after the two oscillations, while the. final surface configuration in basin B, altho appearing more irregular, seems closer to the initial configuration. Thus it may be concluded that the serrated basin seems to give a somewhat larger error in period, a somewhat smaller error in topography.

The same cases were run with a coriolis parameter $\mathrm{f}=.0001 \mathrm{sec}-\mathrm{t}$, corresponding to latitude 43 degrees $\mathrm{N}$ (but of course the large size of the basin makes a model with constant $f$ unrealistic). In this the initial configuration will not be attained again, and so all that was done was to compare the configuration in the two basins after an arbitrary time lapse (180 iterations). Here the difference in surface topography (figures 6 and 7) might be largely due to the fact that basin A seems to propagate the gravity seiche more rapidly than $\mathrm{B}$, and the two basins were not really compared at the same seiche phase. No comparison is made with a theoretical solution.

In summary, it seems that the results from the serrated basin are surprisingly good and close to the theoretical results. Other difficulties related to discretization seem to be more severe than the serrated nature of the grid boundary.

\section{Acknowledgements}

The author is grateful to PERTAMINA (Bagian Pengolahan Data), particularly to Dr. E. Soenredi, for allowing use of their IBM-360 computer 
for the computations, to Bank Negara Indonesia - 1946, particularly to Adnan Achmad, for allowing use of their keypunches, to Dr. Mulia Sidjabat and R. Kastoro for help and advice. Appreciation is expressed to Lembaga Penelitian Laut and its staff, particularly to Birowo Sujatno, for use of their facilities. This work was supported by SEAMEC and Smithsonian Institute thru a grant from Rockefeller Foundation, and by U.S. National Science Foundation thru Grant GA-17137.

\section{References}

Brettschneider, G., 1967: Anwendung des Hydrodynamische-Numerischen Ver-fahrens zur Ermittlung der Mo-Mitschwingungsgezeit der Nordsee. Mitteilungen des Instituts fuer Meereskunde" der Universitat Hamburg, Nr. VII, January 1967.

Neumann, J. v. and R. D. Richtmyer, 1950: A method for the numerical calculation of hydrodynamic schocks, J. Appl. Physics, 21, 232-237.

Figures

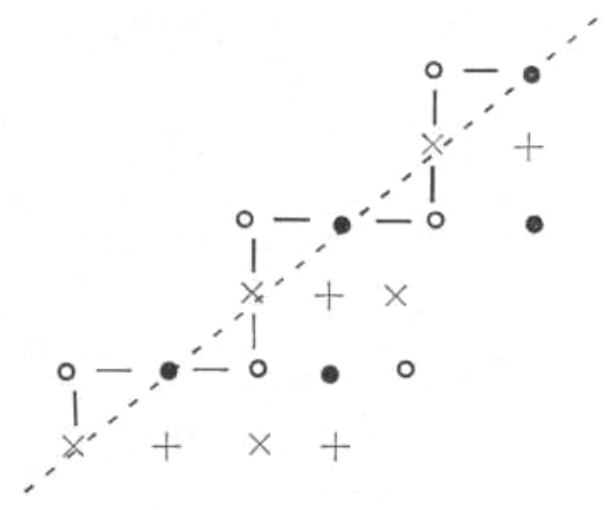

Figure 1. Hansen grid for a boundary (dotted line) inclined 45 degrees to grid axes. The symbols,$+ x$,., and o represent grid points at which $Y$, U, $\mathrm{V}$ and nothing, respectively, are calculated. The dashed line represents the serrated grid boundary. 


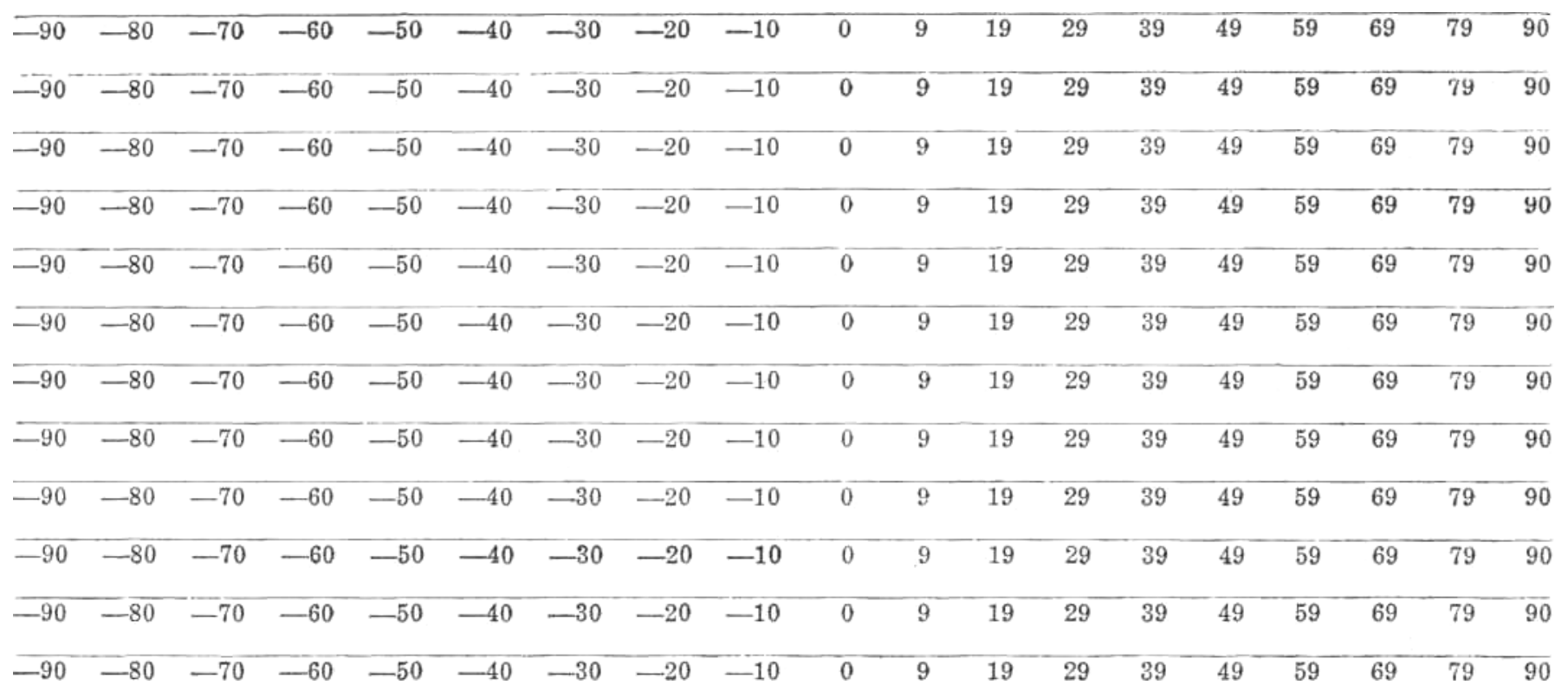

Figure 2. Initial configuration of surface elevation (on arbitrary scale) for the basin A (unserrated). North is upward. The initial velocity field is taken to be zero. 
60

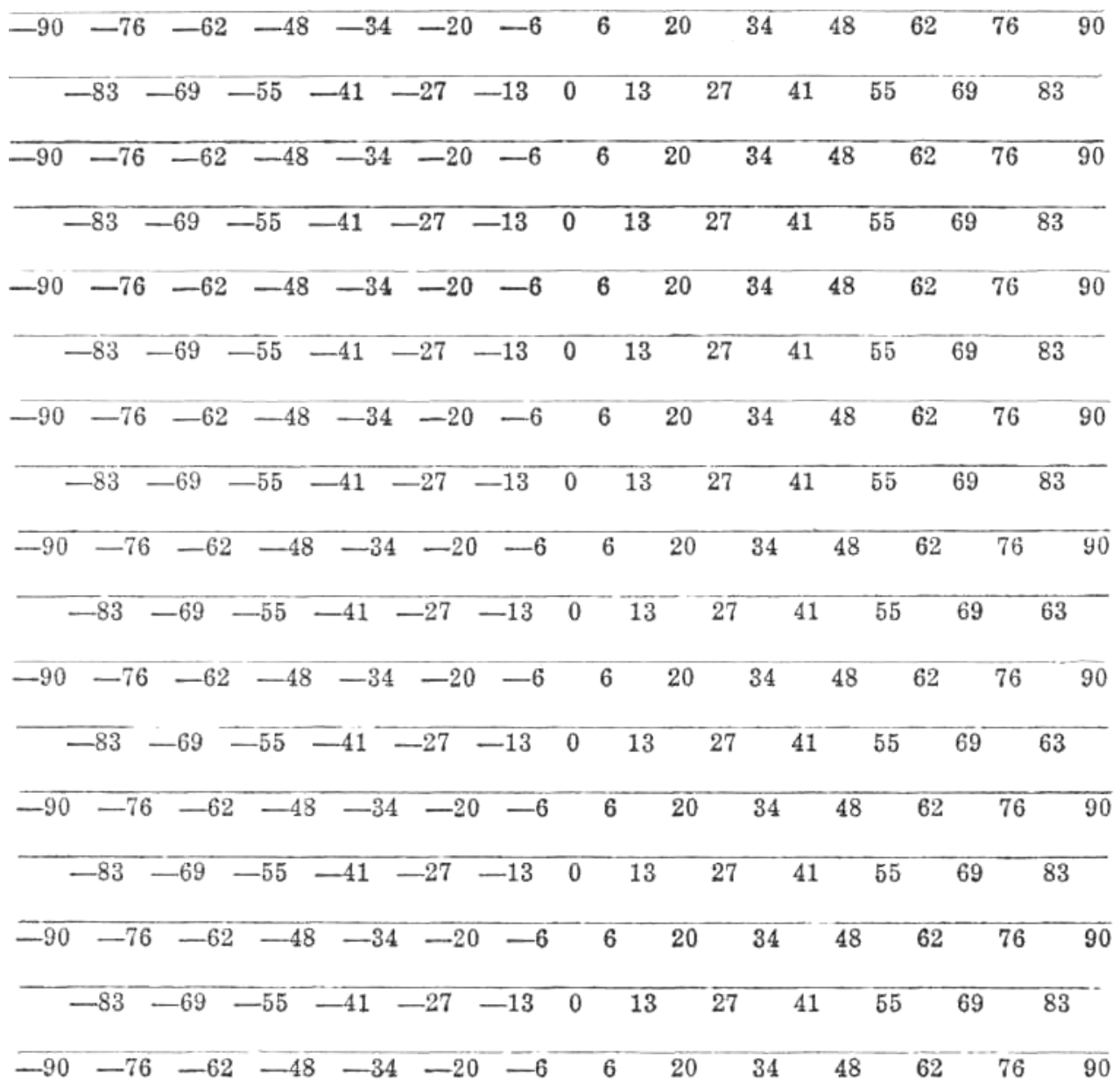

Figure 3. Initial configuration of surface elevation (on arbitrary scale) for basin B (serrated). Northeast is upward. The initial velocity field is taken to be zero. 


\begin{tabular}{lllllllllllllllll}
\hline-85 & -80 & -72 & -60 & -48 & -37 & -28 & -20 & -12 & 0 & 12 & 20 & 28 & 37 & 48 & 60 & 72 \\
\hline-85 & -80 & -72 & -60 & -48 & -37 & -28 & -20 & -12 & 0 & 12 & 20 & 28 & 37 & 48 & 60 & 72 \\
\hline-85 & -80 & -72 & -60 & -48 & -37 & -28 & -20 & -12 & 0 & 12 & 20 & 28 & 37 & 48 & 60 & 72 \\
\hline-85 & -80 & -72 & -60 & -48 & -37 & -28 & -20 & -12 & 0 & 12 & 20 & 28 & 37 & 48 & 60 & 72 \\
\hline-85 & -80 & -72 & -60 & -48 & -37 & -28 & -20 & -12 & 0 & 12 & 20 & 28 & 37 & 48 & 60 & 72 \\
\hline-85 & -80 & -72 & -60 & -48 & -37 & -28 & -20 & -12 & 0 & 12 & 20 & 28 & 37 & 48 & 60 & 72 \\
\hline-85 & -80 & -72 & -60 & -48 & -37 & -28 & -20 & -12 & 0 & 12 & 20 & 28 & 37 & 48 & 60 & 72 \\
\hline-85 & -80 & -72 & -60 & -48 & -37 & -28 & -20 & -12 & 0 & 12 & 20 & 28 & 37 & 48 & 60 & 72 \\
\hline-85 & -80 & -72 & -60 & -48 & -37 & -28 & -20 & -12 & 0 & 12 & 20 & 28 & 37 & 48 & 60 & 72 \\
\hline-85 & -80 & -72 & -60 & -48 & -37 & -28 & -20 & -12 & 0 & 12 & 20 & 28 & 37 & 48 & 60 & 72 \\
\hline-85 & -80 & -72 & -60 & -48 & -37 & -28 & -20 & -12 & 0 & 12 & 20 & 28 & 37 & 48 & 60 & 72 \\
\hline-85 & -80 & -72 & -60 & -48 & -37 & -28 & -20 & -12 & 0 & 12 & 20 & 28 & 37 & 48 & 60 & 72
\end{tabular}

Figure 4. Configuration of surface elevation in basin A (unserrated) after 194 iterations with $\mathrm{f}=0$. The actual time elapsed is 2 (194) At $=21.6$ hours, and is approximately two complete periods of the numerical solution. 
62

$$
\begin{aligned}
& =\begin{array}{lllllllllllllll}
\hline 93 & -79 & -67 & -53 & -33 & -15 & -5 & 5 & 15 & 33 & 53 & 67 & 76 & 93
\end{array} \\
& \begin{array}{lllllllllllll}
-85 & -73 & -61 & -43 & -24 & -10 & 0 & 10 & 24 & 43 & 61 & 73 & 85
\end{array}
\end{aligned}
$$

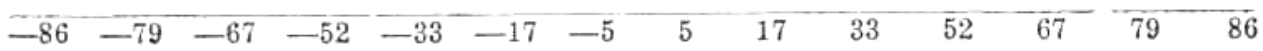

$$
\begin{aligned}
& \begin{array}{lllllllllllll}
-82 & -74 & -60 & -43 & -25 & -10 & 0 & 10 & 25 & 43 & 60 & 74 & 82
\end{array}
\end{aligned}
$$

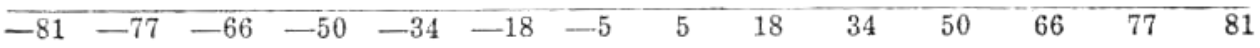

$$
\begin{aligned}
& \begin{array}{lllllllllllll}
-77 & -71 & -57 & -41 & -26 & -11 & 0 & 11 & 26 & 41 & 57 & 71 & 77
\end{array}
\end{aligned}
$$

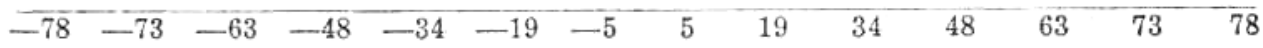

$$
\begin{aligned}
& \begin{array}{lllllllllllll}
-74 & -67 & -55 & -40 & -27 & -11 & 0 & 11 & 27 & 40 & 55 & 67 & 74
\end{array}
\end{aligned}
$$

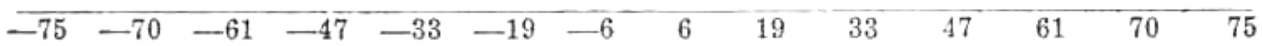

$$
\begin{aligned}
& \begin{array}{llllllllllll}
-74 & -67 & -55 & -40 & -27 & -11 & 0 & 11 & 27 & 40 & 55 & 67
\end{array} \\
& \begin{array}{llllllllllllll}
\hline-78 & -73 & -63 & -48 & -34 & -19 & -5 & 5 & 19 & 34 & 48 & 63 & 73 & 78
\end{array} \\
& \begin{array}{lllllllllllll}
-77 & -71 & -57 & -41 & -26 & -11 & 0 & 11 & 26 & 41 & 57 & 71 & 77
\end{array}
\end{aligned}
$$

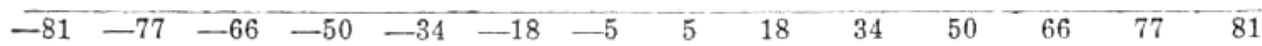

$$
\begin{aligned}
& \begin{array}{lllllllllllll}
-82 & -74 & -60 & -43 & -25 & -10 & 0 & 10 & 25 & 43 & 60 & 74 & 82
\end{array}
\end{aligned}
$$

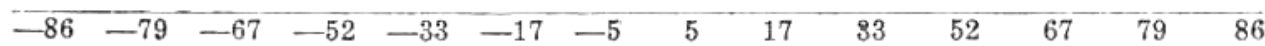

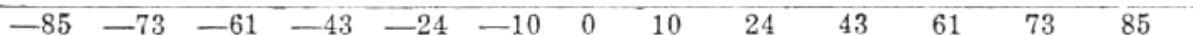

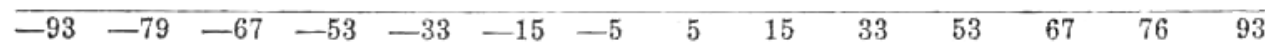

Figure 5. Configuration of surface elevation in basin B (serrated) after 200 iterations with $\mathrm{f}=0$. The actual time elapsed is $2(200) \Delta \mathrm{t}=22.2$ hours, and is approximately two complete periods of the numerical solution. 


\begin{tabular}{rrrrrrrrrrrrrrrrrrrrrr}
\hline-59 & -63 & -66 & -65 & -64 & -63 & -62 & -60 & -55 & -50 & -46 & -41 & -40 & -39 & -37 & -35 & -32 & -3 \\
\hline-55 & -59 & -61 & -59 & -58 & -56 & -55 & -53 & -48 & -43 & -38 & -33 & -32 & -31 & -29 & -28 & -26 & -2 \\
\hline-50 & -53 & -55 & -52 & -50 & -48 & -47 & -45 & -40 & -35 & -30 & -25 & -23 & -22 & -21 & -20 & -18 & -2 \\
\hline-41 & -45 & -46 & -44 & -41 & -39 & -37 & -36 & -31 & -26 & -21 & -16 & -14 & -13 & -11 & -10 & -9 & -1 \\
\hline-31 & -35 & -36 & -33 & -31 & -28 & -27 & -25 & -0 & -16 & -11 & -6 & -4 & -3 & -1 & 0 & 1 \\
\hline-19 & -23 & -24 & -22 & -20 & -18 & -17 & -15 & -10 & --5 & 0 & 4 & 6 & 7 & 9 & 11 & 13 & 1 \\
\hline-7 & -11 & -13 & -11 & -9 & -7 & -6 & -4 & 0 & 5 & 10 & 15 & 17 & 18 & 20 & 22 & 24 & 2 \\
\hline 4 & 0 & -1 & 0 & 1 & 3 & 4 & 6 & 11 & 16 & 20 & 25 & 27 & 28 & 31 & 33 & 36 & 3 \\
\hline 15 & 11 & 9 & 10 & 11 & 13 & 14 & 16 & 21 & 26 & 31 & 36 & 37 & 39 & 41 & 44 & 46 & 4 \\
\hline 24 & 20 & 18 & 20 & 21 & 22 & 23 & 25 & 30 & 35 & 40 & 45 & 47 & 48 & 50 & 52 & 55 & 5 \\
\hline 30 & 27 & 26 & 28 & 29 & 31 & 32 & 33 & 38 & 43 & 48 & 53 & 55 & 56 & 58 & 59 & 61 & 5 \\
\hline 34 & 32 & 32 & 35 & 37 & 39 & 40 & 41 & 46 & 50 & 55 & 60 & 62 & 63 & 64 & 65 & 66 & 6 \\
\hline
\end{tabular}

Figure 6. Configuration of surface elevation in basin A (unserrated) after 180 iterations with $\mathrm{f}=.0001 \mathrm{sec}^{-}$. 


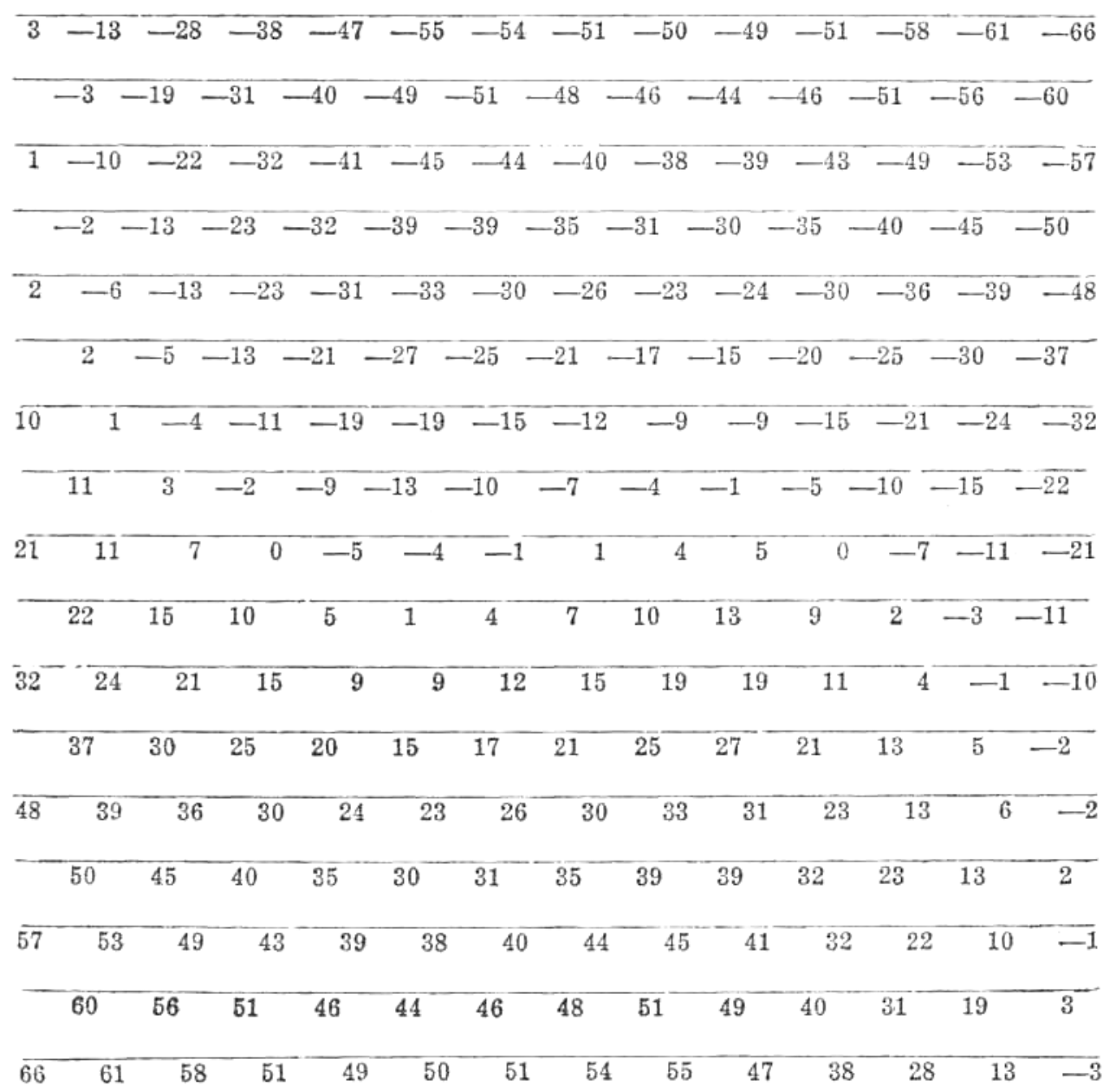

Figure 7. Configuration of surface elevation in basin B (serrated) after 180 iterations with $\mathrm{f}=0.0001 \mathrm{sec}^{-}$. 